\title{
ČLANCI
}

Prof. dr WOLFGANG ROHRBACH

European Academy of Sciences and Arts, Salzburg

e-mail: consult@uniqa.rs

pregledni rad

UDK 94(=163.41)(436-89)"1848/1908"

primljeno: 31. oktobar 2016.

327(497.11:436-89)"1848/1908"

prihvaćeno: 23. novembar 2016.

321.61:929 Франц Јозеф I

\section{KAISER FRANZ JOSEPH I UND DIE SERBEN 1848-1908}

ZUSAMMENFASSUNG: Kaiser Franz Joseph regierte 68 Jahre die durch ebenso viele spezifische Errungenschaften wie auch Konflikte charakterisierte $k(u) k$ Monarchie. Während seiner Regierungszeit herrschten in Russland vier Zaren, von denen einer, Nikolaus I (1825-1855) 1849 den jungen Franz Joseph im Kampf gegen die revoltierenden Ungarn militärisch unterstützte. Man weiß heute über die freundschaftlichem Beziehungen und Abkommen Kaiser Franz Josephs mit den serbischen Monarchen des Hauses Obrenović sowie mit serbisch-orthodoxen Kirchenoberhäuptern, serbischen Militärs, Wissenschaftlern und Künstlern viel mehr als noch vor der Jahrtausendwende. Die historische Forschung hat Kaiser Franz Joseph gut eingeordnet und etliche Vorurteile über ihn und König Milan entkräftet. Darüber hinaus kommen auch immer noch neue Dokumente ans Licht. Damit wurde dem Mythos, dass seitens Österreichs in den Beziehungen zu Serbien über Jahrhunderte politische Gegensätze vorherrschend gewesen seien, eine wissenschaftlich fundierte Argumentation entgegen gesetzt. Der vorliegende Beitrag dokumentiert und interpretiert $z$. T. in Vergessenheit geratene bis 1848 zurückreichende Gemeinsamkeiten und Kooperationen von Österreichern und Serben. Auf Betreiben des Kaisers wurden zahlreiche hohe militärische, wissenschaftliche und politische Positionen mit Serben besetzt; Künstler erhielten Aufträge im Zuge der Umgestaltung der Kaiserstadt Wien. An der Universität Wien entstand 1849 das weltweit älteste Institut für Slawistik. Die Universität Wien wurde in den nächsten Jahren zur Schnittstelle wissenschaftlicher Entwicklungen und gesellschaftlicher Koordination des Balkans.

SCHLÜSSELWÖRTER: Ausgleich, Austroslavismus, Banat, Berliner Kongress, Bosnien, Milan I Obrenović, Militärgrenze (Krajina), Okkupation, Revolutionsjahre 1848/49, Ringstraße 


\section{Ein Monarch an der Wegscheide der Geschichte}

Vor hundert Jahren, am 21. November 1916, starb im Schloss Schönbrunn Kaiser Franz Joseph I im 86. Lebensjahr. Niemand repräsentiert heute als übermächtige Symbolfigur das alte Österreich besser. Trotz Ablehnung monarchischer Staatsstrukturen nach 1918 wurden die Franz Joseph-Büsten und Bilder im republikanischen Österreich insbesondere in Wien nie beseitigt. In der prunkvollen Eingangshalle des Kunsthistorischen Museums am Ring prangt eine Kaiserbüste; im Sitzungssaal des Ministerrats am Ballhausplatz hängt bis heute ein pompöses Kaisergemälde, ebenso im Festsaal der Industriellenvereinigung am Schwarzenbergplatz. Aber auch Bezeichnungen von Straßen und Bauwerken erinnern an den Kaiser: Franz Josefs-Kai, Franz Josef-Bahnhof. Das „Sozialmedizinische Zentrum Süd“ nennen die Wiener bis heute Franz Josefs-Spital. ${ }^{1}$

Karl von Habsburg, das gegenwärtige Oberhaupt der Familie Habsburg-Lothringen gab im März 2016 folgenden Kommentar ab: „Es ist erstaunlich, dass ein Mensch, der vor 100 Jahren gestorben ist, immer noch so populär ist. Ich kann mir diese Popularität vor allem dadurch erklären, dass er für eines der wesentlichen Elemente der Monarchie gestanden ist; für Kontinuität." 21848 brachen in ganz Europa Unruhen aus. In der Habsburgermonarchie war der vollständige Kollaps des verhassten Metternichschen Systems Anlass zur Revolution. In Wien begann die Revolution am 13. März $1848 .^{3}$ Die Ereignisse des Jahres 1848 verdeutlichten auch die Führungsschwäche Kaiser Ferdinands und zeigten, dass er krankheitsbedingt nahezu regierungsunfähig war. Am 2. Dezember 1848 legte Ferdinand offiziell die Regierung nieder; den persönlichen Kaisertitel behielt er bis zu seinem $\operatorname{Tod}^{4}$, und Franz Joseph wurde im Thronsaal der fürstbischöflichen Residenz von Olmütz, wohin der Hof zu Beginn des Wiener Oktoberaufstands geflohen war, zum neuen Kaiser proklamiert. ${ }^{5}$ Etliche Episoden der Revolution hatte der junge Franz Joseph vor seiner Inthronisierung als Beobachter miterlebt, wie aus Berichten seines Beichtvaters bekannt ist. „Das waren Tage!" war der einzige Kommentar.

${ }^{1}$ Herbert Lackner, „Der verklärte Kaiser“, Historie Profil Thema das Beste aus Österreichs unabhängigen Nachrichtenmagazin, 1 (2016), 22.

${ }^{2}$ Karl von Habsburg, „Vorwort zur Aufsatzsammlung, Kaiser Franz Joseph I zum 100. Todestag'“, History. Kurier das österreichische Geschichtsmagazin, 1 (2016), 6.

${ }^{3}$ Georg Bönisch, „Durchlaucht, das ist eine Revolution“, Der Spiegel Geschichte, 3 (2014), 52 .

${ }^{4}$ Allerhöchstes Patent vom 2. Dezember 1848.

${ }^{5}$ Wien seit 60 Jahren. Zur Erinnerung an die Feier der 60-jährigen Regierung Seiner Majestät des Kaisers Franz Josef I. der Jugend Wiens gewidmet von dem Gemeinderate ihrer Vaterstadt (Wien: Gerlach \& Wiedling, 1908). 
Aber auch zwei serbische Herrscher waren Beobachter und Zeitzeugen der 1848-er Revolution in Wien. Der eine war der nach seiner Absetzung in Belgrad etwa sechs Jahre (1847-1853) im Wiener Exil lebende Fürst Miloš Obrenović, und der andere sein 1842 ebenfalls abgesetzter Sohn Fürst Mihajlo. Beide wohnten damals im 1.Wiener Bezirk, Annagasse 12. Wien bzw. Österreich war für Serben, die aus dem Osmanischen Reich, Ungarn etc. in die Residenzstadt übersiedelten, mit wirtschaftlicher und politischer Besserstellung verbunden. Dies hatte der Wissenschaftler Ami Boué schon in seinem 1841 in französischer Sprache erschienenen Werk über die Europäische Türkei“ hervorgehoben. 1889 erschien die Deutschübersetzung, in welcher es heißt: „Ebenso wie Walachen haben die Serben das Leid, sich unter verschiedenen Herrschaften verteilt zu sehen, ohne große Hoffnung auf dereinstige Vereinigung, außer unter österreichischem Zepter...". ${ }^{6}$ Diese Zusammenhänge wurden Franz Joseph schon als Knabe im Französisch-und Geographie-Unterricht nähergebracht.

Der aufwendige Unterricht seit frühester Kindheit hatte seine guten Gründe. Einen wichtigen Abschnitt im Ausbildungsprogramm, das auch künftige Expansions-Chancen der Monarchie aufzeigen sollte, stellte das Wissen um die Militärgrenze dar. Diese (lateinisch confinium militare, serbisch/kroatisch „Vojna Krajina“) war vom 16. bis zum 19. Jahrhundert die Bezeichnung für das zum Schutz errichtete Militärgebiet des Habsburgerreiches an der Grenze zum Osmanischen Reich. Es umfasste die Kroatische Militärgrenze und seit dem 17. und 18. Jahrhundert die Slawonische sowie die Banater und die Siebenbürger Militärgrenze.

In das Grenzland wurden seit Jahrhunderten gezielt serbische und walachische Wehrbauern angesiedelt. Sie genossen eine Reihe kaiserlicher Privilegien. Wer von ihnen jedoch die Offizierslaufbahn einschlagen wollte, trat meist vom serbisch-orthodoxen Glauben zum römisch-katholischen über. Erst dann durfte er die Militärakademie absolvieren. Das wichtigste Amt im Bereich der Militärgrenze war das des Generals oder Bans. Es lag meist in der Hand des kroatischen Hochadels. Zu Zeiten ihrer größten Ausdehnung von 1764 bis 1851 war die Grenze mit bis zu 17 Regimentern (bestehend aus je vier Bataillonen) mit etwa 17.000 Mann ständig besetzt. ${ }^{7}$

Auf die Unterstützung der Serben, Walachen und Kroaten konnten sich die österreichischen Monarchen in Krisenzeiten verlassen. Das zeigte sich 1848/49. Als Dank adelte oder zeichnete Kaiser Franz Joseph später etliche verdiente Offiziere aus, die Wehrbauernfamilien entstammten. Josip Jelačić fiel mit seinen Truppen am 11. September 1848 in Ungarn ein,

${ }^{6}$ Ami Boue, Die Europäische Türkei (Wien: Mell, 2008), 344.

7 "(Klein-)Krieg entlang der Militärgrenze“, Die Welt der Habsburger, www.habsburger. net > Kapitel > klein-kri...; abgefragt am 19.8.2016. 
woraufhin am 15. September ein ung. Landesverteidigungsrat (Vorsitzender Kossuth) gebildet wurde. Im Gegenzug ernannte der Wiener Hof am 25. September Graf Majlath zum Statthalter und Graf Lamberg zum militärischen Oberbefehlshaber in Ungarn.

In dieser Phase unternahm der General des Fürstentums Serbiens, Stevan Petrović Knićanin (1809-1855) eine militärische Hilfsaktion zugunsten Jellacic, der jedoch kein Erfolg beschieden war. Constantin Wurzbach liefert dazu in seinem Biographischen Lexikon folgende Hinweise: „Ursprünglich Kaufmann ging er 1832 in die Umgebung des Fürsten Miloš, auf den er großen Einfluss ausübte. 1848 stellte er sich an die Spitze einer Freischar von 3.000 Mann, die den österreichischen Serben gegen die aufständischen Ungarn zur Hilfe kommen sollte. Er wurde zum Nationalobersten und General ernannt, musste jedoch vor den Ungarn den Rückzug über die Theiß antreten. Für seine Verdienste im Kampf gegen die Revolution in Ungarn wurde er auf Betreiben Franz Josephs Ritter des Maria-TheresiaOrdens." 8

Im August 1849 kapitulierte die ungarische Armee. Schon 1849 gab der Kaiser bekannt, dass er den Sieg über die Revolution keineswegs zur Wiedererrichtung der alten Ordnung nutzen werde. Er wollte einen imperial "großösterreichischen" zentralistischen Staat, der nicht auf den alten feudalen Strukturen aufbaute, sondern sich auf eine neue Bürokratie und die Armee stützte. Letztere sollte über allen Nationen stehen. Der Kaiserhof sollte als Machtzentrum den Einheitsstaat regieren. Die rechtliche Grundlage bildete das „Silvesterpatent“ vom 31. Dezember 1851. Der Kaiser hatte ab nun die alleinige Entscheidungsgewalt. Das erste Dezennium der Franzisko-Josephinischen Ära (1849-1858) ging als Neo-Absolutismus in die Geschichte ein.

\section{Des Kaisers Dank an Krajina-Serben}

Kaiser Franz Joseph dankte den Krajina Serben und Walachen ihre Treue, die sie in den Kämpfen der Jahre1848/49 bewiesen hatten, einerseits mit militärischen Beförderungen und Auszeichnungen, andererseits mit Gebietsaufwertungen. Als größte Belohnung erhielten die Serben 1850 ein eigenes Kronland mit der Bezeichnung „Woiwodschaft Serbien und Temescher Banat", das aber leider nach der Niederlage des Kaisers in der Schlacht von Solferino (1859) auf Druck der Magyaren Anfang 1860 wieder aufgelöst wurde. 1849 wurde die in vier Generalate unterteilte Militärgren-

${ }^{8}$ Biographisches Lexikon des Kaisertums Österreich. entnommen Constantin von Wurzbach, (Wien: Kaiserlich-königliche Hof- und Staatsdruckerei, 1864), XXII, s. v. Stephan Knicanin. 
ze ein eigenes Kronland. ${ }^{9}$ Serben bzw. serbische Offiziere zog es seit 1849 verstärkt in die Metropole „ihres“: Kaisers bzw. nach Österreich, um am kulturellen Leben teilzunehmen. Junge Serben wurden zum Studium nach Wien geschickt; Offizieren wurden ehrenvolle Aufgaben übertragen mit anschließender Ehrung. Stellvertretend für andere seien als Beispiele die Biografien zweier Krajina-serbischer Offiziere angeführt, Petar Preradović und Gavrilo Rodić.

Petar Preradović wurde 1818 im Dorf Grabrovnica nahe Virovitica geboren, das damals zur österreichischen Militärgrenze gehörte. Seine Eltern zählten zur serbisch-orthodoxen Religionsgemeinschaft. Petar strebte die Laufbahn eines Berufssoldaten des kaiserlichen Heeres an und erhielt seine Ausbildung 1830-1838 an der Theresianischen Militärakademie in Wiener Neustadt, die er als einer der Jahrgangsbesten abschloss. In Wiener Neustadt konvertierte er zum Katholizismus und begann hier erste Gedichte in deutscher Sprache zu schreiben. 1848 kämpfte er als Hauptmann gegen die italienische Einigungsbewegung. Nach seiner Rückkehr nach Kroatien im Jahre 1849 wurde er militärische Elitekaft des Banus Josip Jelačić. 1852 erfolgte seine Beförderung zum Major, 1859 zum Oberst, als welcher er in Temesvar eingesetzt war. Im Jahre 1864 wurde er in Anbetracht seiner militärischen Verdienste geadelt. 1865 war er in Verona eingesetzt und 1866, als Österreich gegen den Verlust der Lombardei kämpfte, erfolgte die Beförderung zum Generalmajor und Brigadier. Preradović verfasste sein dichterisches Werk in deutscher, serbischer und kroatischer Sprache unter dem Einfluss (sprach) nationaler Romantik; seine Gedichte spiegeln oft Panslawistische Ideen wider. Er interessierte sich stark für den Spiritismus und verfasste auch einige einschlägige Artikel darüber. Sein Leben verlief im Spannungsfeld zwischen militärischer Karriere, Politik und Literatur. Petar Preradovic starb 1872 in Fahrafeld bei Pottenstein, im Erzherzogtum Österreich unter der Enns. ${ }^{10}$ Seine Enkelin, die in Wien geborene Paula Preradovic, wurde die Verfasserin des Textes der heutigen österreichischen Bundeshymne (1947).

Gavrilo Rodić wurde 1812 in Gvozd (Vrginmost), einer Gemeinde mit überwiegend serbischen Bewohnern in der Gespanschaft (=Komitat) SisakMoslavina in Kroatien geboren. Er war ein Adeliger serbischer Abstammung und General der k.u.k. Armee. Er zog zuerst 1835 als Grenzoffizier durch ein Gefecht gegen aufständische Begs unter Hussein Berbirli Aga in Bosnien die Aufmerksamkeit auf sich, kämpfte 1848/9 unter Ban Jelačić gegen die Ungarn und wurde 1851 Oberst, 1859 für seine Verteidigung der

${ }^{9}$ Jakob Amstadt, Die k. k. Militaergrenze 1522-1881 (Würzburg: Dissertation, 1969), 49.

${ }^{10}$ Biographisches Lexikon des Kaisertums Österreich. entn. Constantin von Wurzbach, (Wien: K.u.K. Hof- und Staatsdruckerei, 1872), XXIII, 263-265, s. v. Preradović, Peter von. 
Bucht von Kotor (kroat. Boka kotorska; ital. Bocche di Cattaro) gegen die französische und italienische Flotte. 1866 trug er als General des 5. Armeekorps wesentlich zum Siege von Custozza bei. Nachdem er 1869 den Aufstand in der Bucht von Kotor, beschwichtigt hatte, wurde er 1870 zum Statthalter des Kronlandes Dalmatien ernannt und war darauf bedacht, die Italiener mehr und mehr zurückzudrängen und die Südslaven zur Geltung zu bringen. Er war bei diesen daher sehr beliebt und hieß der „alte Gabriel“ (stari Gavro). 1881 abberufen, als Feldzeugmeister verabschiedet, geadelt und als Freiherr zum Mitglied des Herrenhauses ernannt, zog er sich nach Wien zurück, wo er 1890 starb. $^{11}$

In der Franzisco- Josephinischen Epoche wurden in Wien und anderen Universitäts-Städten Österreichs Wissenschaft und Lehre stark forciert. Gewiss hingen diese Maßnahmen mit den ehrgeizigen Plänen des Kaisers zusammen, Wien architektonisch, wissenschaftlich und künstlerisch zu einer Weltstadt umzugestalten. Der Einfluss Wiens fand nunmehr auch in die serbische Kultur Eingang. Es handelte sich um eine außerordentliche geistige Einigkeit, deren Grundlage die gemeinsame orientalischorthodoxe Religion bzw. die im Zentrum Wiens am Fleischmarkt existierende gemeinsame Serbisch-Griechisch-Orthodoxe Kirchengemeinde bildete. Auf diese Weise schufen Griechen, Serben und Aromunen im Rahmen des Wiener Kulturmosaiks eine besondere Schicht von Wissenschaftlern, Künstlern, Großkaufleuten und Bankiers, deren Vertreter auch rasch in die höchsten gesellschaftlichen Schichten des österreichischen Staates aufsteigen konnten. Auch diesen Repräsentanten bot sich Gelegenheit, auch in den Adelsstand erhoben zu werden; sei es aufgrund militärischer Verdienste oder aufgrund ihres Großgrundbesitzes sowie besonderer Leistungen in Wirtschaft und Wissenschaft. Wörtlich heißt es in D. Medakovićs Werk: „Den Höhepunkt der Aufnahme dieses neuen europäischen Geistes bildet die Epoche der Früh- und Hochromantik. ${ }^{12}$

Eine Vorreiter-Rolle nahm in diesem Zusammenhang Fürst Miloš Obrenović ein. Der Fürst galt schon vor dem Revolutionsjahr 1848 in Wien als berühmtester serbischer Großhändler, der mit Hilfe der „k. u. k. priv. Donau-Dampfschifffahrts-Gesellschaft" (DDSG) von Serbien aus auf dem Wasserweg Wien mit Borstenvieh versorgte. Im Gegenzug transportierte er österreichische Möbel, Porzellangeschirr und Musikinstrumente nach Serbien. Miloš veranstaltete auch in den Grazien Sälen in Wien 3 im Jahre1846 den ersten Serben- Ball. Johann Strauss Sohn komponierte dazu die Serbenquadrille, die Fürst Milos seinem Sohn, Fürst Mihajlo, widmete.

${ }^{11}$ Ibid., XXVI, 220-223, s. v. Rodich, Gabriel Freiherr.

${ }^{12}$ Dejan Medaković, Serben in Wien (Novi Sad: Prometej, 2001), 22, 349. 
Weitere Bälle folgten. ${ }^{13}$ Politisch bezweckten diese Unterhaltungsveranstaltungen, möglichst viele Serben in Wien anzuwerben, um Miloš bzw.seinen Sohn wieder die Fürstenposition in Belgrad zu sichern.

Der Austroslavismus als ideologisches Programm der Slaven unter habsburgischer Herrschaft sah im österreichischen Kaiserstaat den optimalen politischen Rahmen für die Existenz der slavischen Völker Zentraleuropas. Diese Gedankenwelt entwickelte sich schon zu Beginn des 19.Jhs als ein spezifischer Zweig des Panslavismus. Als Pionier des Austroslavismus gilt Jernej Kopitar (1780-1844), ein slowenischer Gelehrter aus Krain, dessen Wirkungsstätte Wien war, wo er zunächst als Zensor in der Polizeihofstelle, später als Leiter der Handschriftenabteilung der Wiener Hofbibliothek wirkte.

Der Austroslavismus sah in der Habsburgermonarchie die Hüterin der slavischen Völker. Nur im Rahmenwerk des Kaiserstaates könnten die slavischen Kleinvölker Schutz vor deutschen Hegemoniebestrebungen finden und sich auf kulturellem und politischem Gebiet entfalten. Der Austroslavismus lehnte aber auch den auf das orthodoxe Russland fokussierten Panslavismus ab. ${ }^{14}$ Wien war um die Mitte des 19.Jahrhunderts ein Kultur- und Wirtschaftszentrum der Slaven; insbesondere der Südslaven. Während die westslavischen Sprachen in der Monarchie den Rang gut entwickelter Kultursprachen aufwiesen, fehlte dieses Element bei den Südslaven. Die Grenzen zwischen Sprachen und Dialekten waren fließend und unübersichtlich. Dieser philologische Missstand passte insbesondere bei den Serben und Kroaten keinesfalls zu den hohen Positionen, die sie in Militär, Wirtschaft, Kunst usw. einnahmen. Aber Franz Joseph war als Knabe im Französischunterricht auch auf die Sprache und Kultur der Serben aufmerksam geworden.

1840 war nämlich in französischer Sprache Ami Boue's Werk über die „Europäische Türkei“ erschienen, in welchem der Wissenschaftler nicht nur die Wohnorte und Traditionen der Serben beschreibt, sondern auch auf die Serbische Sprache näher eingeht. In der posthum 1889 erschienenen Deutschübersetzung von Boues Werk lautet der diesbezügliche Text: „Die Serben besitzen eine große Zahl schöner Dichtungen, und diese letzteren allein müssten Jedem zur Pflicht machen, ihre Sprache zu studieren, wenn man nicht endlich heutzutage doch das Bedürfnis fühlte, in jede sorgfältige Ausbildung auch die Kenntnis einer slavischen Sprache einzubeziehen. Ist

${ }^{13}$ Serben-Quadrille op. 14 (1846), gewidmet dem Fürsten von Serbien Mihailo Obrenović.

${ }^{14}$ Andreas Moritsch, Der Austroslawismus : ein verfrühtes Konzept zur politischen Neugestaltung Mitteleuropas (Wien / Köln / Weimar: Internationalen Zentrums für Europäische Nationalismus- und Minderheitenforschung, 1995). 
es nicht mehr als lächerlich, in manchen Hauptstädten Professoren des Chinesischen oder des Sanskrit zu sehen, während man an einen Lehrstuhl für das Slavische, die Sprache der guten Hälfte der Europäer, gar nicht denkt. “15 Nach Gründung des Instituts für Slavistik an der Alma Mater Rudolphina (Universität Wien) wurde auf Anraten des Innen- und Bildungsministers Graf Stadion zunächst der Slowene Franz Miklosich 1849 als außerordentlicher, im Jahr darauf als ordentlicher Professor auf den neu geschaffenen Lehrstuhl für Slavische Philologie an der Universität Wien berufen, den er bis 1886 innehatte. In seinen Vorträgen und Schriften betonte Miklosich immer wieder, dass keine anderen Sprachen einander so ähnlich seien, wie das Serbische und Kroatische. Diese Thesen führten zu einer engen Kooperation mit dem Sprachwissenschaftler Vuk Stefanović Karadžić.

Das Wiener Sprachabkommen von 1850 ist der Grundstein für die Entstehung der Serbokroatischen Schriftsprache. In Wien trafen einander serbische und kroatische Philologen und Schriftsteller um, politisch bedingt, an einer gemeinsamen Schriftsprache zu arbeiten. Diesem Treffen ging eine große Sprachreform in Serbien hervor. Vuk Stefanović Karadžic reformierte die serbische Sprache. Das damals gesprochene „Slavenoserbische" war eine Sprache die russische, kirchenslavische und volkssprachliche Elemente hatte. Angeregt durch die deutschen Gelehrten Jacob und Wilhelm Grimm, nahm er die Sprache in der das Volk sprach als Grundlage einer neuen Serbischen Sprache. Karadžić wählte den ostherzegovinischen "stokavischen Dialekt. Diese Reform war durchaus politisch bedingt, das Ziel: die Loslösung vom russischen Einfluss. Politische Motivation, hier der Widerstand zur Magyarisierung mit der Kroatien damals zu kämpfen hatte, war auch in Kroatien der Grund, warum der Wunsch nach Vereinigung mit anderen Südslawen gegeben war. Die sprachpolitische Bewegung, der Illyrismus, an der Spitze mit Ljudevit Gaj, propagierte die gemeinsame Sprache aller Südslawen. Interessant ist, dass die Sprachbezeichnung „serbokroatisch" aus dem deutschen Sprachraum von Jakob Grimm stammt. ${ }^{16}$ Die gemeinsame Sprache hatte zwei Varianten: die so genannte östliche Variante (Serbisch: kyrillisch, ekawisch) und die westliche Variante (Kroatisch: lateinisch, ijekawisch). Obwohl es politische Antagonismen zwischen Serben und Kroaten gab, wurde die Frage der sprachlichen Einheit bis zum Ende des Ersten Weltkriegs nicht angetastet.

${ }^{15}$ A. Boue, op. cit., 358.

16 Hana Stojić, Phraseologische Untersuchungen zu tierbezogenen Redewendungen Deutsch - B/K/S (Wien: Diplomarbeit, 2009). 


\section{Das Ende des Neoabsolutismus und der Ausgleich von 1867}

In den 1860-er Jahren waren dem Monarchen schmerzliche Niederlagen und einige Siege beschieden, die aber letztendlich wegen schlechter politischer Verhandlungstaktik trotzdem zu Gebietsverlusten für Österreich führten. Unter dem Österreichisch-Ungarischen Ausgleich versteht man die verfassungsrechtlichen Vereinbarungen, durch die das Kaisertum Österreich in die Doppelmonarchie Österreich-Ungarn umgewandelt wurde.

Nach der Niederlage im Deutschen Krieg von 1866 war Kaiser Franz Joseph I. gezwungen, die offenkundige Beschränkung der inneren Autonomie in den Ländern der ungarischen Krone, wie sie nach der Niederschlagung der ungarischen Revolution und des Freiheitskrieges von 1848/1849 absolutistisch festgelegt wurde, aufzuheben. Der passive Widerstand der führenden magyarischen Schichten gegen den Einheitsstaat machte eine Fortsetzung der bisherigen Regelung unmöglich.

Die Verhandlungen über den Ausgleich mit dem Königreich Ungarn wurden Anfang 1867 abgeschlossen. Am 8. Juni 1867 kam es zur Krönung Franz Josephs I. als König von Ungarn in Budapest. Die Länder der ungarischen Krone waren nun von Österreich innenpolitisch unabhängig; vor allem bei Außenpolitik und Militär bestand der Monarch aber auf einer Realunion zwischen Österreich (juristisch und politisch in Österreich oft Cisleithanien genannt) und Ungarn (Transleithanien) Kaiser Franz Joseph I. war zwar faktisch ungarisches Staatsoberhaupt Nr. 1, aber sein Einfluss auf die innenpolitische Situation des Vertragspartners war deutlich kleiner als erhofft. So war er machtlos gegen die Repressalien der ungarischen Regierung gegen jene Serben der nunmehr ungarischen Vojvodina und des Banats, die weiterhin mit Wien kulturelle und wirtschaftliche Beziehungen pflegen wollten. Die Betrübtheit der Serben drückt am besten der Artikel von Svetozar Miletić „Tucidanski članak“ (1860) aus, in dem der Gedanke deutlich zum Ausdruck kommt, dass die Serben nichts mehr in Wien zu suchen hätten". Aber gerade in diesem Jahr entstand in Wien die Serbische Kirchengemeinde, die als Ersatz für die verloren gegangene politische Bedeutung, ein kirchlich-kulturelles Monument darstellen sollte. 1868 wurde gleichsam als nationaler Akt der Serben die Vojvođanska banka gegründet, als eines der ältesten Unternehmen Serbiens existiert sie bis heute.

Viele geschäftstüchtige Serben wurden damals in den Ruin gedrängt, wie der folgende zeitgenössische Bericht zeigt: Von 1867 bis zu seinem Tod im Jahre 1902 wohnte Theodor Stefanović Vilovski in Wien. Er vermerkt in seinen Aufzeichnungen „Moje uspomene“ (Meine Erinnerungen 1867-1881), dass die Serben bis 1866 durchwegs wohlhabend waren und in der Wiener Wirtschaft eine bedeutende Rolle spielten. Leider änderte sich das ab 1867 
(Ausgleich). Der Großteil der mächtigen und angesehenen Serben zog sich aus Wien in die nunmehr für sie zuständige ungarische Hauptstadt Budapest zurück. Große Firmen der Wiener Serben wie z. B. Veličković, Mirović usw. gingen zugrunde und zogen etliche serbische Kleinunternehmen, mit denen sie eng zusammengearbeitet hatten, mit in den Ruin. ${ }^{17}$

Deshalb schmerzte die neue politische Regelung den Großteil der Serben Wiens, und Dejan Medaković kommentiert den Verlust der Wiener „Vaterschaft" und des serbischen Staatsterritoriums: „Hier hätten die Serben eine eigene Versammlung, eine politische und gerichtliche Selbstverwaltung gehabt, ihre Sprache wäre zur Amtssprache geworden. Ein Wojwoda stünde an der Spitze der Exekutivgewalt, sie hätten eine eigene Flagge, ein eigenes Wappen usw. gehabt. All diese schönen Wünsche zerstörte der Österreichisch-Ungarische Ausgleich aus dem Jahre 1867." ${ }^{18}$ Serben traten in der Folge nunmehr als Nutzer und Teilnehmer der für künstlerische, wissenschaftliche und politische Darbietungen geschaffenen Ringstraßenbauten in Erscheinung, einige waren auch direkt mit der (Innen) Ausstattung der Bauten befasst, wie die folgenden Beispiele zeigen:

Uroš Predić (1857-1953) war einer der bedeutendsten serbischen Maler des Realismus, der auch im Projekt Ringstraßen- Prunkbauten mitwirkte. Er ist besonders bekannt für seine monumentale historische Malerei „Kosovka devojka“, genauso wie für seine vielen Portraits.

Uroš Predić studierte an der Wiener Kunstakademie von 1876-1879. Das Parlamentsgebäude an der Wiener Ringstraße, in dem die beiden Kammern des österreichischen Parlaments tagen, wird umgangssprachlich auch als „das Parlament" bezeichnet. Es wurde von 1874 bis 1883 nach einem Entwurf von Theophil von Hansen im neoklassizistischen Stil errichtet. Die Innendekoration im Sitzungssaal des Herrenhauses wurde Prof. Christian Griepenkerl anvertraut. Dieser wiederum überließ die umfangreichen Arbeiten an der Gestaltung des Bilderfrieses mit Szenen aus der griechisch- römischen Mythologie und Geschichte Uroš Predić. Der serbische Maler arbeitete an diesem Fries in den Jahren 1884/85. Leider wurde das Werk Predić im Zweiten Weltkrieg zerstört. Doch ist eine Mappe des Künstlers mit der Aufschrift „Skizzen“ erhalten geblieben. Darin befinden sich kommentierte Bilder seiner Kunstwerke.

Pavle Paja Jovanović wurde 1859 in Vršac geboren und starb 1957 in Wien. Er war ein serbisch-österreichischer Maler des Realismus, der 1877

${ }^{17}$ Theodor Stefanovic-Vilovsky, Die Serben im südlichen Ungarn, in Dalmatien, Bosnien und in der Herzegovina (Wien und Teschen, 1884).

${ }_{18}$ Zitiert in: Wolfgang Rohrbach, Auf den Spuren der Serben Österreichs/Eine historisch-soziologische Aufsatzsammlung (Wien: Österreichisch-Serbischen Gesellschaft, 2013, 107). 
an der Wiener Kunstakademie zu studieren begann. Von 1877 bis zu seinem Tod wirkte er als angesehener Orientmaler, der stark von seinem Lehrer Prof. Leopold Karl Müller beeinflusst wurde. Bereits an der Akademie erhielt Jovanović erste Auszeichnungen und ein dreijähriges kaiserliches Stipendium. Von 1895 an malte Jovanović meistens historische Themen. Nach 1905 fertigte er ausschließlich Porträts europäischer Adeliger und Großbürger an.

Im Jahr 2001 schrieb der damalige Präsident der Serbischen Akademie der Wissenschaften und Künste, Prof. Dejan Medaković, über Paja Jovanović: „Den größten Teil seines langen und überaus fruchtbaren Arbeitslebens verbrachte er in Wien, sodass solch der Ausdruck 'eingewienert' völlig zurecht auf ihn bezieht. Eine solche Behauptung kann auch durch die Tatsache belegt werden, dass sogar das offizielle Portrait Kaiser Franz Joseph I, das im Hauptsaal des Österreichischen Parlaments hing, von Paja Jovanović stammte. Eine größere Anerkennung war zu jener Zeit wohl kaum vorstellbar." 19

\section{Kirchliche und weltliche Vereine der Serben}

In der Ära des Staatskanzlers Metternich, der in jeglichen Zusammenkünften revolutionäre Hintergründe vermutete und sie a priori unterband, waren Vereinsgründungen nur erschwert möglich. Das änderte sich in der Liberalen Ära grundlegend. Schon das Patent vom 26. November 1852 ermöglichte Vereinsgründungen jeglicher Art unter liberalen Voraussetzungen. Die Bewerber hatten nunmehr spezifische Bedingungen zu erfüllen, um ihre Konzessionen zu erhalten: Was das Kulturleben der Serben in Wien betrifft, so spielten die seit 1860 gegründeten verschiedenartigen Vereine eine wichtige Rolle. ${ }^{20}$ Dass es erst 1860 zur Gründung einer eigenständigen Serbischen Kirchengemeinde kam, hatte mehrere Gründe.

${ }^{19}$ D. Medaković, Serben in Wien, 271-2.

${ }^{20}$ Engagierter Vorläufer der Serbischen Kirchengemeinde war die aus Griechen und Serben zusammengesetzte christlich-orthodoxe Gemeinde St. Georg. Im letzten Quartal des 18. Jhs gab es aber in Wien Gruppen serbisch- und griechisc h-orthodoxer Stadtbewohner, die sich in der Donaumetropoleals Alteingesessene fühlten. Sie wollten sich von jenen nur vorübergehend in Wien weilenden Orthodoxen aus dem Osmanischen Reich unterscheiden. Daher beschlossen die Wiener bzw. k. k. Serben und Griechen schon im Jahre 1786, eine weitere Kirchengemeinde zu gründen. Die Privilegien dazu wurden ihnen von Kaiser Joseph II. im Jänner 1787 erteilt und im Oktober 1796 von Kaiser Franz II. bestätigt. Im ersten Drittel des 19. Jhs existierten somit zwei griechisch-serbische Gotteshäuser im Zentrum Wiens. Ab nun galt die Regelung, dass die Dreifaltigkeitskirche den privilegierten österreichischen Untertanen mit griechischen oder serbischen Wurzeln für Gottesdienste dienen solle. Die ältere St. Georgskirche hingegen stand für die serbischen und griechischen Untertanen des Osmanischen Reichs oder orthodoxen Nichtösterreicher zum Besuch ihrer Got- 
Der serbische Patriarch Josif Rajičić sah sich veranlasst 1853 und 1860 Petitionen an Kaiser Franz Joseph I zu richten, er möge die Gründung einer eigenen Serbischen Kirchengemeinde und eines ebensolchen Gotteshauses genehmigen. Der Patriarch begründete seine Bitte, dass Serben und Romanen mangels einer eigenen Kirche keine Predigten und Informationen in ihrer Muttersprache hören könnten. Er erinnerte auch daran, dass in Wien zwar zwei orientalisch- orthodoxe Kirchen existieren, sie könnten aber die Bedürfnisse der Serben nicht befriedigen. „Denn in ihnen wird der Gottesdienst nunmehr in Griechisch gehalten, einer Sprache, die den Serben und Romanen unverständlich ist." Angesichts der Verdienste, welche die Serben durch Jahrhunderte als kaisertreue Untertanen aber auch durch ihre Handelsbeziehungen als Untertanen des Sultans in Wien erworben hätten, schlug er vor, zwei zusätzliche Kirchen in Wien zu erbauen; eine für slavische und eine für romanische Gottesdienste. ${ }^{21}$

Am 17. September 1860 erhielt Patriarch Rajičić eine kaiserliche Nachricht, dass sie Serben gleich nach der Wahl eines Verwaltungsrates mit dem Sammeln von Spenden für den Bau einer Kirche samt Pfarrhof und Schule beginnen könnten. Als am 5. Oktober 1860 die kaiserliche Nachricht als Handschreiben auf Seite 1 der Wiener Zeitung veröffentlicht wurde, gab es eine Überraschung. Der freundlichen Anrede „Lieber Patriarch Rajačić!" folgte einige Zeilen weiter der Hinweis, dass Kaiser Franz Joseph kostenlos ein Grundstück (in der Veithgasse) für den Bau der Kirche zu Verfügung stellen werde. Auf Einladung des Patriarchen Rajačić kamen am 4. November 1860 vornehme Serben zur Konstituierung und Wahl eines provisorischen Verwaltungsrates zusammen, welcher der zuständigen Niederösterreichischen Behörde sofort die von Dr. Djordje Stojaković erstellten Statuten der Serbischen Kirchengemeinde zur Genehmigung vorlegen sollte. Stojaković war Gründer und Obmann, der sofort angesehene Wiener Bürger serbischer Abstammung als Mitglieder aufnahm. Die ersten Mitglieder waren Kosta Nenadović, Ognjeslav Utješinović-Ostrožinski, Jovan Vladislav, Dimitrije Mirović und Jovan Veličković. ${ }^{22}$

Über die ersten Jahre der Kirchengemeinde (bis 1866) gibt es relativ wenige Aufzeichnungen, doch dann wurden interessante Details dokumentiert. Den Aussagen Theodor Stefanović Vilovsky zufolge war die Serbische

tesdienste zur Verfügung. Willibald M. Plöchl, Die Wiener Orthodoxen Griechen (Wien: Verlag des Verbandes der Wissenschaftlichen Gesellschaften Österreichs, 1983), 27.

${ }^{21}$ Die wichtigsten Teile der Petitionen des Patriarchen Rajačić sind abgedruckt in: D. Medaković, Serben in Wien, 87.

${ }^{22}$ Denkschrift zum 75-jährigen Jubiläum der Serbisch - orthodoxen Kirchen- und Schulgemeinde in Wien 1860-1935 (Beograd, 1936), 15-19. 
Kirchengemeinde im Zeitraum von 1867 bis 1880 sowohl zahlenmäßig, als auch hinsichtlichdes Ranges ihrer Mitglieder überaus mächtig. ${ }^{23}$

Über die Zeit danach gibt es genauere Aufzeichnungen. So hielt sich der Serbische Arzt und Dichter, Jovan Jovanović Zmaj mehrere Male in Wien auf. Seinem Tagebuch der Jahre 1882-1888 sind Hinweise zu entnehmen, die von der Teilnahme Zmajs am Leben der Kirchengemeinde zeugen. Über die Art der doppelten Lebensführung Zmajs als Mediziner und Künstler urteilte sein Freund Mladen Leskovac, dass er „eher ein serbischer Dichter als ein Wiener Arzt war." Er suchte die Einsamkeit, um sich schöpferisch mit der Dichtung oder dem Verfassen von Artikeln für seine Zeitschriften zu beschäftigen. $^{24}$

Die größten Anstrengungen der damaligen Serben in Wien, und insbesondere der Serbischen Kirchengemeinde waren auf die eigene Konsolidierung bzw. der Errichtung eines den höchsten musikalischen Anforderungen entsprechenden Kirchenchors und den Bau eines eigenen Gotteshauses ausgerichtet. Der Chor musste jedoch vor 1893 seine Darbietungen -mangels einer eigenen Kirche - in Konzert, Theater-und Ballsälen abhalten.

Am 21. November 1890 wurde in der Veithgasse mit dem Bau der Kirche nach Plänen des Architekten Heinrich Wagner begonnen. In der Ausschusssitzung vom 3. März 1891 konnte mit Wohlwollen die Nachricht aufgenommen werden, dass Kaiser Franz Joseph I „veranlasst habe, dass aus staatlichen Mitteln unserer Kirchengemeinde eine Unterstützung von fünf Tausend (5000) Forint bewilligt wird." An die Kirchengemeinde dachte aber auch der ehemalige serbische König Milan I. Obrenović als er 1000 Forint für den Bau spendete. ${ }^{25}$ Der Bau der Kirche und des vierstöckigen Hauses der Kirchengemeinde dauerte volle drei Jahre. Für die Kirche selbst wurden ein Teil des Erdgeschoßes und die ganze Etage verwendet, sodass in ihr etwa 300 Menschen Platz fanden. Am 19. November 1893 wurde das Gotteshaus im Beisein von Kaiser Franz Joseph und Ministerpräsident Fürst Alfred III. zu Windisch-Grätz (1851-1927) feierlich eingeweiht. Erster Pfarrer der Serbisch-orthodoxen Kirche zum Hl. Sava wurde Mihajlo Mišić, der bis zu seinem Tode im Jahre 1924 seine hoch angesehene Parochie leitete. ${ }^{26}$

Gutgläubigkeit, Fleiß und Disziplin waren im 19.Jh die von der Jugend geforderten Tugenden. Der bedeutendste Jugendverein der Serben Wiens war der 1863 gegründete Verein „Zora“. Seine verschiedenartigsten

${ }^{23}$ D. Medaković, Serben in Wien, 163.

${ }^{24}$ Vasa Stajić, Jovan Jovanović Zmaj (Novi Sad: Slavija, 1935), 33-37.

${ }^{25}$ D. Medaković, Serben in Wien, 87.

${ }^{26}$ Vukosava Mišić, Postanak i razvitak Srpske Pravoslavne crkve u Beču (Beograd: Štamparija Sv. Save, 1929), 5-10. 
Veranstaltungen wurden allmählich mit bedeutenden kulturellen Inhalten angereichert. In seinen Erinnerungen machte Theodor Stefanovic Vilovsky Notizen über alle jene Ereignisse, die mit der Konzerttätigkeit der "Wiener Gesellschaft Zora" zu tun hatten. Stellvertretend für andere sei eine Feier erwähnt, welche die Gesellschaft Zora 1876 im Saal der Gartenbaugesellschaft organisierte. Ein Teil des Programms war ein serbisches weibliches Harfenquartett, welches damals für die Wiener eine Neuigkeit darstellte. Weitere Melodien spielte ein serbisches Orchester unter der Leitung des Wiener Konzertmeisters Karl Michael Zierer. Der serbische akademische Verein „Zora“ setzte in der darauffolgenden Zeit seine schon zur Tradition gewordenen Rhetorikabende fort. So organisierte er am 14. Jänner 1897 einen Rhetorikabend mit anschließendem Ball im Ronacher (unweit der Ringstraße). Aufgrund der rasch wachsenden Mitgliederzahl wurden in Form von Soireen Voraussetzungen für bedeutsame gesellschaftliche Aktivitäten des Vereins geschaffen.

Das Leben in der Residenzstadt Wien erforderte auch die Gründung gesellschaftlicher Organisationen mit humanitären Inhalten. Als Beispiel sei der Arbeiterverband „Sloga“ mit Sitz in Wien erwähnt über den eigentlich nur ein Gruppenfoto existiert, das am 19. September 1909 aufgenommen wurde. In diesem Verein sollten offensichtlich serbische Arbeiter aus Bosnien jenen Serben aus anderen Teilen der Monarchie nähergebracht werden. ${ }^{27}$ Aufmerksamkeit verdient aber auch der „Unterstützungsverein für arme serbische Studierende an den Hochschulen in Wien“, dessen Vorsitzender der Parochus der Serbisch-orthodoxen Kirche in Wien, Mihajlo Mišić, war. In einem Aufruf des Jahres 1909, in welchem der Verein um Geldspenden bat, hieß es, dass die Wiener Bürger serbischer Abstammung" diesen Verein gegründet haben, um diese armen Studenten nach Möglichkeit zu unterstützen, geleitet von dem Glauben, dass mit der Zeit aus ihnen eine dem serbischen Volk treu ergebene Intelligenz wird. “28

\section{Pulverfass Balkan: Ursachen und Folgen der Okkupation Bosniens}

Im letzten Quartal des 19. Jhts veränderte eine Reihe von schicksalhaften Ereignissen - allem voran der stufenweise Niedergang des Osmanischen Reiches - die Einstellung serbischer bzw (süd)slavischer Volksgruppen zueinander und zu Österreich. Dabei verdrängte der allen Ortes aufflammende Nationalismus kosmopolitische Ziele.

${ }^{27}$ D. Medaković, Serben in Wien, 349.

${ }^{28}$ Andrija Matić, Nešto iz života i rada društva 'Zora'; književni rad srpskog đačkog društva u Beču (Wien, 1875), 16-7. 
Erschwerend wirkte im 19.Jh hinsichtlich der Zuordnung der Untertanen auch das in der Donaumonarchie praktizierte Territorialprinzip. Man sprach zB nicht von Serben, der in Kroatien wohnhaft und geadelt worden waren, sondern von „kroatischen Adeligen serbischer Abstammung“; der Hinweis auf die Abstammung entfiel später oft. In der nationalen und internationalen Geschichtsschreibung fand bis weit ins 20.Jh hinein auch eine weitere Tatsache wenig Beachtung, die im Zusammenhang KroatenKatholiken und Serben-Orthodoxe von Bedeutung ist. Durch die Probleme, die der österreichische Kaiser am Ende 19. Jhs mit diversen Slavengruppen hatte, wurde erstmals die Nationalität der Menschen am Balkan über die Religion definiert. Auch nationale Strömungen in Kroatien und Serbien trugen zu dieser Entwicklung bei. Katholische Südslaven wurden nun zu Kroaten, unabhängig ob sie in Montenegro, Serbien, Bosnien, Ungarn, im Königreich Dalmatien oder in Kroatien geboren waren. Und wer in den genannten Regionen orthodox war, wurde oder war Serbe. ${ }^{29}$

Was unter den letztgenannten Bevölkerungsgruppen zu verstehen ist, wurde im berühmten Sammelwerk Kronprinz Rudolphs „Österreich- Ungarn in Wort und Bild“ zu erklären versucht: „Die Bevölkerung bestand aus Türken, Serben und Kroaten. Diese Bezeichnungen waren falsch, aber sie hatten sich in Bosnien seit langer Zeit für Moslems, griechisch-orthodoxe Christen und Katholiken eingebürgert. ${ }^{30}$ Zunächst erklärten sich alle politischen und kirchlichen Institutionen mit dieser Lösung einverstanden, doch mit der Okkupation Bosniens gerieten erstmals auf dem (Einfluss) Gebiet der Monarchie Serben/Kroaten gegen Serben/Kroaten in kriegerische Auseinandersetzungen und ein Teil der Serben bezog Stellung gegen Österreich.

Der Russisch- Osmanische Krieg 1877-1878 war eine militärische Auseinandersetzung zwischen dem Russischen Zarenimperium und dem Osmanischen Reich. Der Krieg fand überwiegend auf dem Gebiet Bulgariens statt und endete mit einem Sieg Russlands. Unmittelbare Auslöser des Krieges waren die osmanischen Repressionen gegen die Serben und Bulgaren nach dem Serbisch-Osmanischen Krieg sowie dem bulgarischen Aprilaufstand. Im Rahmen des Panslawismus empfand sich Russland als Schutzmacht dieser Völker. Die gesellschaftliche Stimmung im Zarenreich erforderte ein Eingreifen. Aber Russland verfolgte auch strategische Ziele; nämlich einen von geopolitischen Rivalen freien Zugang zum Mittelmeer. Im Frieden von San Stefano musste das Osmanische Reich die volle Unab-

${ }^{29}$ Helmut Konrad, Österreich-Ungarn: Nationale Fragen in der Donaumonarchie; Universal-Lexikon, www.vga. at/index..abgefragt 30.8.2016.

30 Renate Basch-Ritter, Österreich-Ungarn in Wort und Bild, /Menschen und Länder (Graz-Wien-Köln, 1989), 89. 
hängigkeit Rumäniens, Bulgariens, Serbiens und Montenegros anerkennen und kleinere Gebiete an diese Länder abtreten. ${ }^{31}$ Die Südslaven betrachteten in der Folge dieses Ereignis lange Zeit als die zweite Geburt ihrer nationalen Geschichte. Da jedoch die anderen europäischen Mächte das Gleichgewicht in Europa durch einen überproportionalen Machtzuwachs Russlands gefährdet sahen, wurden die Ergebnisse des russisch-türkischen Friedens von San Stefano auf dem Berliner Kongress in erheblichem Maße eingeschränkt.

Der Berliner Kongress 1878 war ein Schulbeispiel für die „ZweiKlassen- Diplomatie“, die von der Überheblichkeit der Großmächte gegenüber den kleineren Nationen geprägt war, über deren Köpfe hinweg verhängnisvolle Entscheidungen getroffen wurden. ${ }^{32}$ Das Ziel des diplomatischen Gipfeltreffens war die Neuordnung des Balkans. Neben dem Gastgeber Deutschland nahmen Österreich-Ungarn, Russland und Großbritannien teil. Das Osmanische Reich hatte nur Beobachterstatus. ${ }^{33}$

Für Österreich-Ungarn war der Berliner Kongress zwar auf den ersten Blick ein außenpolitischer Erfolg, der sich aber als innenpolitisches Desaster entpuppen sollte. Denn die Okkupation Bosnien-Herzegowinas verschärfte die Nationalitätenfrage, da die Verstärkung des südslawischen Elements das empfindliche Nationalitätenverhältnis verschob. Im Artikel 25 des Berliner Vertrages vom 13. Juli 1878 wurde die österreichischungarische Monarchie ermächtigt, Bosnien und ie Herzegowina unbefristet zu besetzen und zu verwalten. Auch im Sandschak Novi Pazar wurde der Donaumonarchie durch den Berliner Kongress die militärische Kontrolle zugestanden, der ansonsten aber beim Osmanischen Reich verblieb. Dies diente dem Zweck, eine südslawische und damit prorussische Machtbildung auf dem Balkan zu verhindern, wenn etwa Serbien und Montenegro sich vereinigten. Dementsprechend groß war der serbische Widerstand. ${ }^{34}$

Die Vertreter der Deutschnationalen und der extremen Magyaren sahen in der Okkupation dieses ökonomisch rückständigen Gebietes ein Ergebnis einer rein dynastisch begründeten Profilierungssucht, die den eigenen nationalen Interessen widersprach.

Zwischen dem 29. Juli und 20. Oktober 1878 wurde das Gebiet (51.027 km²), das eine gemischte Bevölkerung (1.142.000 Einwohner) von

${ }^{31}$ Ian Drury, The Russo-Turkish War 1877 (London: Osprey, 2012).

32 „Der Berliner Kongress und die Aufteilung des Balkans“, Der Erste Weltkrieg ww1.habsburger. net > kapitel > der-berli...; abgefragt am 24.8.2016.

${ }^{33}$ Bertrand Michael Buchmann, Österreich und das Osmanische Reich. Eine bilaterale Geschichte (Wien: Facultas, 1999).

34 Imanuel Geiss (Hrsg.), Der Berliner Kongreß 1878. Protokolle und Materialien (Boppard am Rhein: Boldt, 1978). 
orthodoxen Serben (43\%), katholischen Kroaten (18\%) und Muslimen (Bosniaken) (39 \%) aufwies, militärisch erobert. Die Okkupation traf wider Erwarten - Andrassy sprach zuvor von einem „Spaziergang mit einer Blasmusikkapelle" - auf ernsthaften militärischen Widerstand. Dieser kam vor allem von der zuvor dominierenden moslemischen Mittelschicht, aber teilweise auch von der serbisch-orthodoxen Bevölkerung. Diese Gruppe kämpfte für einen Anschluss Bosniens an Serbien. Durch diese massive Gegenwehr musste der militärische Kraftaufwand der k.u.k. Armee erhöht werden.

Die Hauptarmee zur Okkupation Bosniens überschritt unter Joseph Philippovich von Philippsberg, dem Befehlshaber des 13. Armeekorps die Grenze über die Save bei Kostajnica und bei Gradiška. Die Abteilungen vereinigten sich bei Banja Luka, dort folgte der Vorstoß nach Jajce. Seine Karriere entsprach voll der eines wegen der Offizierslaufbahn zum Katholizismus konvertierten Krajina-Serben. K. k. Feldmarschall-Lieuten-ant Joseph Freiherr Philippovic von Philippsberg wurde zu Gospić im Licaner Grenzbezirk Kroatiens im Jahre 1818 geboren. Gospić lag von 1583 bis 1882 im Bereich der Kroatischen Militärgrenze, gehörte zum Königreich Kroatien und Slawonien und 1867 bis 1918 zum ungarischen Teil der Donaumonarchie. Joseph Philippovic trat am 1. November 1834 bei dem 1. GrenzRegiment in die kaiserliche Armee und kam im April 1836 zum Pionniercorps, in welchem er im April 1839 zum Unterleutnant befördert wurde. Ende September 1843 zum General-Quartiermeisterstab transferiert, wurde er zu gleicher Zeit Oberleutnant und am 20. September 1847 Hauptmann. Am 13. November 1848 wurde er zum Major im WarasdinerKreutzer-Regimente befördert, kam aus demselben am 12. September 1851 unter gleichzeitiger Ernennung zum Oberstleutnant und Flügel-Adjutanten zum großen Generalstab, wo er verblieb, bis er am 1. Jänner 1853 zum Obersten im 5. Grenz-Regiment ernannt wurde. ${ }^{35}$

Am 19. April 1859 zum General-Major und Brigadier in Semlin befördert, wurde er mit Allerh. Handbillet Franz Josephs I vom 14. Juni 1864 anlässlich der Wahl des griechisch-unierten Erzbischofs und Metropoliten zu Karlowitz zum kaiserlichen Kommissär bei dem illyrischen Nationalcongresse und bei der Synode ernannt, welche auf diesem Kongress wegen der Bischofswahl zusammentrat. Im Juli 1878 übernahm Philippovich Befehl über die zum Einmarsch nach Bosnien bestimmten Truppen und unterwarf diese Länder im Okkupationsfeldzug in Bosnien der österreichischen Herrschaft. Es kam dabei aber zu einem erheblichen Widerstand von

35 Biographisches Lexikon des Kaisertums Österreich. entnommen Constantin von Wurzbach (Wien: Kaiserlich-königliche Hof- und Staatsdruckerei, 1870), XXII, 210, s. v. Philippović von Philippsberg, Joseph Freiherr. 
Partisanen, vor allem von muslimischen Kämpfern unter Derwisch Hadschi Loja (Hadži-Loja). Verstärkt wurde der Widerstand durch Soldaten und Offiziere der regulären Osmanischen Armee, die offiziell das Gebiet zu übergeben hatten. ${ }^{36}$ Am 19. August wurde Sarajevo, nach Artilleriebeschuss aus 52 Geschützen und heftigem Straßenkampf eingenommen. Noch am Tag vor der Eroberung ließ Philippovich den osmanischen Gouverneur für Bosnien Hafiz Pascha inhaftieren.

Der Häuserkampf in der bosnischen Hauptstadt, die damals 50.000 Einwohner hatte, forderte durch die Guerillataktik der Verteidiger zahlreiche Opfer. Philippovich berichtete: „Es entspann sich einer der denkbar grässlichsten Kämpfe. Aus jedem Hause, aus jedem Fenster, aus jeder Tür spalte wurden die Truppen beschossen; ja selbst Weiber beteiligten sich daran. Das fast ganz am westlichen Stadteingange gelegene Militärspital, voll von kranken und verwundeten Insurgenten.." 37 Die aufständischen Bosnier zogen sich nach der Einnahme von Sarajevo in die umliegenden Berge zurück und leisteten noch wochenlang Widerstand mittels Guerillataktik. Philippovich kehrte 1880 nach Wien und 1882 als Landeskommandierender von Böhmen nach Prag zurück.

Die 18. Division drang von Dalmatien mit 9000 Mann unter General Stephan von Jovanović entlang der Neretva in die Herzegowina ein. Am 5. August wurde Mostar erobert. Stephan Freiherr von Jovanović (kroatisch: Stjepan barun Jovanović), ('1828 in Pazarište (nahe Gospić), KroatienSlawonien; $\nmid 1885$ in Zadar /ital. Zara) war ein kroatischer Adliger und Feldmarschallleutnant der k.u.k. Armee. Jovanović trat 1845 in das habsburgische (österreichisch-ungarische) Heer ein und kämpfte 1848-49 unter Radetzky in Italien. 1850 wurde er in den Generalstab versetzt und später Adjutant des im Süden Dalmatiens agierenden Generals Gabriel Freiherr von Rodich. Zwischen 1861 und 1865 befand sich Jovanović als Generalkonsul Österreichs in Sarajevo. Als ausgezeichneter Kenner Bosniens, Montenegros, der Herzegowina und der Krivošije kehrte er 1865 als Oberst in den Militärdienst zurück. 1866 konnte er sich im Krieg gegen Italien auszeichnen.

Als der Aufstand in Dalmatien ausbrach, erhielt Jovanović 1869 in Kotor (Cattaro) den Befehl über eine Gebirgsbrigade und blieb dort, nachdem die Aufständischen durch Verhandlungen zur Einstellung der Feindseligkeiten veranlasst worden waren. 1875 wurde er in den Frei-

${ }^{36}$ Rainer Egger, „Philippovich von Philippsberg Josef Frh..“, in: Österreichisches Biographisches Lexikon 1815-1950 (ÖBL). (Wien: Verlag der Österreichischen Akademie der Wissenschaften, 1983), Band 8, 44.

${ }^{37}$ Karl Sommeregger, „Philippovic von Philippsberg, Josef Freiherr“, in: Allgemeine Deutsche Biographie (Leipzig: Duncker \& Humblot, 1907), Band 53, 54. 
herrenstand erhoben und 1876 zum Feldmarschallleutnant ernannt. 1877 übernahm er in Split (Spalato) den Oberbefehl über die 18. Truppendivision. Im Jahr darauf führte er die Besetzung der Herzegowina aus und unterwarf das gesamte Land binnen weniger Tage und fast ohne Verluste. Er wurde dort dann auch als Oberbefehlshaberund Leiter der Verwaltung eingesetzt. 1882 hatte er den Aufstand in der Krivošije zu unterdrücken und wurde anschließend Statthalter in Dalmatien und Militärkommandant in Zadar. Für seine Leistungen erhielt er am 2. Mai 1879 das Ritterkreuz des Maria Theresien-Ordens. ${ }^{38}$

Ein bedeutendes Ergebnis des Berliner Kongresses war, dass auf der außenpolitischen Ebene das Bündnis Österreich-Ungarns mit Deutschland vertieft wurde, da Wien auf einen starken Partner gegen Russland angewiesen war. Es kam zum Abschluss des Zweibundes zwischen Berlin und Wien (1879). Weil man sich in der Donaumonarchie nicht entscheiden konnte, zu welcher Reichshälfte die Neuerwerbungen kommen sollten, wurde die Verwaltung durch das gemeinsame k. u.k. Finanzministerium übernommen. Eine Volkszählung im Jahre 1879 ergab eine Gesamtbevölkerung in Bosnien von 1.158.164, die sich zusammensetzte aus: 496.485 GriechischOrtho-doxe/Serben (42,87\%), 448.613 Muslimen (38,73\%), Katholiken/Kroaten 209.391 (18,08 \%), 3.426 Juden und 249 Sonstigen. Für diese Bevölkerungsgruppen schuf die k.u.k. Verwaltung ein leistungsfähiges Schul- und Sanitätswesen und ermöglichte eine gute wirtschaftliche Entwicklung. In dieser Zeit begann die industrielle Auswertung der Bodenschätze und Wälder Bosnien-Herzegowinas, wobei jedoch mit Augenmaß vorgegangen wurde ( $u$. a. Aufforstungsprojekte). Schmalspurige Eisenbahnlinien und wichtige Fernstraßen wurden errichtet. Für die ersten Ansätze der Industrialisierung waren Fachkräfte notwendig. Dies führte 1880-1910 zur Zuwanderung von Menschen aus anderen Teilen der Donaumonarchie. Darunter waren neben Deutschen und Tschechen auch Polen, Slowenen und Ruthenen. Manche dieser Einwanderer erwarben auch Grundbesitz und waren als Bauern tätig.

\section{Franz Joseph I und Milan I}

Als serbisches Staatsoberhaupt fungierte 1868 bis 1882 Fürst Milan IV Obrenović, der 1882 bis 1889 als König Milan I. regierte. Milans Vater war ein gleichnamiger Neffe des Fürsten Miloš Obrenović; seine Mutter die rumänische Adlige Elena Maria Catargiu. Milans Vater diente als Söldner in der rumänischen Armee und fiel 1861 in Bukarest bei einer Schlacht gegen die Türken. Seine Mutter führte nach dem Tod ihres Mannes ein unbe-

38 „Jovanović Stephan Frh. Von“, in: ÖBL, Band 3, 138. 
schwertes Leben und überließ die Erziehung ihres Sohnes seinem Onkel, dem Fürsten Mihailo Obrenović. Milan zog im Alter von sechs Jahren nach Kragujevac, wo er von Erziehern und Gouvernanten betreut wurde. Anschließend besuchte er das Pariser Lycée Louis-le-Grand.

Nachdem sein Onkel Mihailo 1868 einem Mordanschlag zum Opfer gefallen war, wurde der noch minderjährige Milan zum Nachfolger auf den serbischen Fürstenthron bestimmt. Bis zu seiner Volljährigkeit 1872 führte der Premierminister und Anführer der serbischen Liberalen, Jovan Ristić, als Prinzregent die Aufgaben des jungen Fürsten. Ristić behielt auch nach Milans Volljährigkeit die Regentschaft und wurde schließlich vom Anführer der Konservativen, Milutin Garašanin, dem Sohn Ilija Garašanins, abgelöst. Zeit seines Lebens sträubte sich Milan Obrenović gegen seine Rolle als konstitutioneller serbischer Fürst, was ihn in schwere Konflikte mit den politischen Eliten des Landes brachte und letztlich seinen Sturz bewirkte.

In Milans Ära entstanden die ersten politischen Parteien in Serbien: die Radikale Partei unter Nikola Pašić (1881), die Liberalen unter Jovan Ristić, sowie Milans eigene Fortschrittspartei (Srpska Napredna stranka). Milan stärkte das Militärwesen in Serbien und forcierte den Umbau des Heeres von einer Miliz in ein stehendes Heer. Obwohl sich Milan außenpolitisch zunächst an Russland anlehnte, bewog ihn die unfreundliche Haltung Zar Alexanders III. anlässlich eines 1881 durchgeführten Besuchs in Sankt Petersburg, Unterstützung bei Kaiser Franz Joseph I von ÖsterreichUngarn zu suchen. 1881 schloss Milan ohne das Wissen und die Zustimmung seiner Regierung ein geheimes Abkommen mit Österreich-Ungarn. Der politische Geheimvertrag vom 28. Juni 1881 gestand ÖsterreichUngarn weitgehende Vorrechte in der Bestimmung der serbischen Außenpolitik zu. So durfte Serbien keine Verträge mit anderen Staaten ohne vorherige Zustimmung der Donaumonarchie abschließen. Ebenso verpflichtete sich Serbien zum Ausbau einer Eisenbahnstrecke von Belgrad Richtung Sofia und Istanbul sowie zur Regulierung der Donau für die Schiffsfahrt. Im Gegenzug würde Österreich-Ungarn Serbien auf internationaler Ebene unterstützen. Die Anerkennung Serbiens als Königreich durch die Großmächte 1882 wurde mit Hilfe der österreichisch-ungarischen Diplomatie erwirkt. Serbien verpflichtete sich auf mindestens zehn Jahre, keine territorialen Ansprüche auf Bosnien, die Herzegowina und den Sandschak sowie Novi Pazar zu stellen. Im Gegenzug hätte es, soweit im Interesse der Donaumonarchie, freie Hand im Süden gegenüber dem Osmanischen Reich bzw. Makedonien und Bulgarien.

Innenpolitisch verpflichtete sich Serbien, auf seinem Territorium keine gegen Österreich-Ungarn gerichtete großserbische oder panslawistische Propaganda zuzulassen. Kritiker in der serbischen Regierung empfan- 
den das Abkommen als eine ungebührliche Einschränkung der Souveränität, durch die sich Serbien zu einem Vasallenstaat Österreich-Ungarns gemacht habe. Als Reaktion auf die Unterzeichnung des Abkommens bot der Präsident des Ministerrates, Mihailo Piroćanac, einen Rücktritt der gesamten Regierung an, den Milan jedoch nicht annahm.

Serbien geriet in heftige Rivalität mit dem seit 1878 autonomen Fürstentum Bulgarien, dessen deutscher Fürst Alexander von Battenberg mit der Unterstützung Russlands Serbien den Rang auf dem Balkan streitig machte. Als Bulgarien sich 1885 mit Ostrumelien vereinigte, sah Milan darin eine Vorbereitung für einen bulgarischen Feldzug auf Makedonien, und erklärte Bulgarien den Krieg. Er verlor jedoch am 7. November 1885 die entscheidende Schlacht bei Sliwniza gegen die Bulgaren und entging nur knapp einem militärischen Desaster. Eine Invasionsdrohung Österreichs hielt Bulgarien im letzten Augenblick davon ab, in Serbien einzudringen.

Beim Staatsbesuch Franz Josephs in St. Petersburg 1897 wurde der Status Quo auf dem Balkan bestätigt. Einige Jahre davor war Franz Joseph für die Schaffung einer Demarkationslinie auf dem Balkan eingetreten, die eine Russland-und Österreich orientierte Zone schaffen sollte. In den 1890-er Jahren engagierte sich Russland stärker im Fernen Osten, was zum Krieg gegen Japan führen sollte. Weil Wien außenpolitisch immer mehr in Abhängigkeit Berlins geriet, verlor seine Balkanpolitik die bisherige britische Unterstützung. Zugleich wurde der Verbleib Italiens im Dreibund immer fragwürdiger, da es einen Seekrieg mit der starken britischen Flotte vermeiden wollte. Auch nahm das Balkaninteresse Roms zu. Die zunehmenden innenpolitischen Krisen in der Donaumonarchie trugen zusätzlich dazu bei, dass Österreich-Ungarn sich in seiner Balkanpolitik immer stärker am Deutschen Reich orientierte. Während Milans Herrschaft war das serbische Fürstentum nach der erfolgreichen Teilnahme am Russisch-Türkischen Krieg 1878 und dem darauf folgenden Frieden von San Stefano endgültig unabhängig vom Osmanischen Reich geworden. Infolge der rumänischen Königsproklamation im Jahr 1881 wurde am 6. März 1882 das Königreich Serbien proklamiert. $\mathrm{Zu}$ diesem Anlass gratulierte Kaiser Franz Joseph I. Milan persönlich. Der Zar ignorierte das Ereignis.

Im Jahr 1887 versuchten Anhänger der Radikalen Partei ein Attentat auf Milan. In der Öffentlichkeit nahm man ihm übel, dass er seine Ehe mit der russischen Adeligen Natalija Keško mit einigen Affären (unter anderem mit Jennie Churchill) kompromittierte. Schließlich ließ er sich 1888 scheiden. Der Ehe mit Königin Natalija entspross sein Sohn und Thronfolger Aleksandar Obrenović. Den Anstoß zum Thronverzicht Milans gab ein heftiger Kompetenzkonflikt zwischen dem König und der gewählten Regie- 
rung, so dass Milan im März 1889 zu Gunsten seines Sohnes Aleksandar Obrenović abdankte und Serbien verließ.$^{39}$ Nach Aleksandars Volljährigkeit 1893 gewann der aus dem Ausland zurückgekehrte Milan durch seinen Rückhalt im Offizierskorps und den wachsenden Einfluss auf seinen Sohn erneut an Macht. Am 7. Juli 1899 unternahm ein Mitglied der Radikalen Partei erneut ein Attentat auf ihn, woraufhin er die Radikalen erneut verfolgen ließ. Alexander I. ernannte ihn 1897 sogar zum Oberbefehlshaber der serbischen Armee. Die Hochphase Milans war jedoch nur von kurzer Dauer, denn als er sich gegen die Ehe seines Sohnes mit der übel beleumundeten Draga Maschin wandte, verlor er 1900 jeglichen Einfluss auf ihn und musste Serbien erneut verlassen. Milan zog nach Wien, wo er kurz darauf an einer schweren Lungenentzündung erkrankte, die ihm nach Meinung kaiserlicher Ärzte kaum Überlebenschancen ließ. Kaiser Franz Joseph I. überließ ihm ein Haus in der Johannesgasse (Nr. 16) und wies den ungarischen Grafen Eugen Zichy an, Milan Gesellschaft zu leisten. Milan I. starb schließlich am 11. Februar 1901 an den Folgen der Krankheit.

Die telegrafische Nachricht vom Tode König Milans in Wien traf am 11.Feber um 16:30 Uhr im Konak in Nisch ein. Die Wiener Zeitung brachte dazu folgende Meldung: Sofort wurden die Minister aus der Skupschtina in den Konak berufen, wo ihnen der König (Aleksandar) tief erschüttert die Todesnachricht mitteilte. Nach 5 Uhr (Nachmittag) erschienen die Minister wieder in der Skupschtina. Die Verhandlung wurde sofort unterbrochen. Ministerpräsident Jovanovitsch erhob sich und mit ihm alle Abgeordneten. Der Ministerpräsident ergriff das Wort zu folgender Ansprache: (...) „König Milan ist in Wien um 4 Uhr nachmittags verschieden. Die Verdienste des Verblichenen wird die Geschichte beurteilen, wir alle sind jedoch ihrer eingedenk. Die völlige Unabhängigkeit und die Gebietserweiterung Serbiens sind an seinen Namen geknüpft. Die politischen Verhältnisse der letzten Zeit haben ihn zum Verlassen des Landes bewogen, nichtsdestoweniger bleiben seine Verdienste aus der Vergangenheit unvergesslich." 40

Am Donnerstag, dem 14. Februar 1901 brachte die Wiener Zeitung auf ihrer Titelseite die amtliche Meldung: „Auf Allerhöchste Anordnung wird für weiland Seine Majestät König Milan I. die Hoftrauer von Freitag, den 15. Februar 1901, angefangen durch zwölf Tage, ohne Abwechslung, bis einschließlich 26. Februar getragen. ${ }^{" 41}$ In diesem Zusammenhang sei in Erinnerung gerufen: Als die kaiserliche Gattin Sisi im Jahre 1898 einem Attentat zum Opfer fiel, hatte Franz Joseph I eine viertägige Hoftrauer an-

${ }^{39}$ Holm Sundhaussen, Geschichte Serbiens (Wien: Böhlau, 2007).

40 „König Milan +“ ; in: Wiener Zeitung, Nr 35, vom 12. Februar 1901, 6.

${ }^{41}$ Amtlicher Teil/Wiener Zeitung Nr. 37 von Donnerstag, 14. Februar 1901, 1. 
geordnet; nach dem Attentat vom 28.Juni 1914 auf den Thronfolger Franz Ferdinand gab es keinerlei Hoftrauer. Die Wiener Zeitung brachte an diesem Tag aber auch ganzseitig die bis ins letzte Detail geregelte Anordnung über das „Zeremoniell der Überführung, Exponierung und Bestattung der Leiche weiland Seiner Majestät König Milans I." Es handelt sich bei dieser Darstellung um eine der besten historischen Quellen Europas zu königlichen Bestattungszeremonien am Beginn des 20.Jhs.

Einige Details seien im Folgenden angeführt: Nachdem Milan I von 12. bis 14. Februar im Sterbehaus Johannesgasse Nr. 16 aufgebart gewesen war, erfolgte die Überführung, zu der es in der Ankündigung der Wiener Zeitung heißt: „Donnerstag, den 14. Februar 1901, um 10 1/2 Uhr abends wird die Allerhöchste Leiche eingesegnet (...) und auf den bereit stehenden mit sechs Rappen bespannten schwarzen Leichenfourgon gebracht. Trabanten-Leibgarden und Leibgardereiter leisten hierbei die Nebenbegleitung (...). Der Zug nimmt den Weg von der Wohnung (I., Johannesgasse Nr. 16) über die Ringstraße, den Schwarzenbergplatz, den Rennweg in die Veithgasse zur serbischen Kirche. Bei der Kirche wird der Sarg (...) von der Geistlichkeit empfangen. (...) Freitag, den15. Februar, um 8 Uhr früh beginnt der Einlass des Publikums (...) Um 12 Uhr wird der öffentliche Einlass eingestellt." Dass Kaiser Franz Joseph nicht nur an entsprechenden Äußerlichkeiten interessiert war, sondern auch an persönlicher Präsenz zeigt die folgende Passage: „Um vier Uhr findet die feierliche Einsegnung der Allerhöchsten Leiche in der serbischen Kirche statt. Seine k. u. k. Apostolische Majestät und Ihre k. u. k. Hoheiten die durchlauchtigsten Herren Erzherzoge nehmen die Zufahrt beim Hauptportale und begeben sich direkt in die Kirche. Die serbische Gesandtschaft, die fremdländischen Vertreter, die Hof-und Staatswürdenträger, die Präsidien der beiden Häuser des Reichsrates, die Generalität und der Bürgermeister von Wien, sowie die eventuell anwesenden serbischen Deputationen haben sich schon vorher nach Maßgabe des Raumes in oder vor der Kirche eingefunden. (...). “42

Am Samstag, dem 16. Februar 2016 brachte die Wiener Zeitung unter der Kolumne „Kleine Chronik/König Milan + " einen Abschlussbericht über die Trauerfeierlichkeiten, in welchem unter anderem betont wurde: „...Se. Majestät der Kaiser und mehrere erlauchte Mitglieder des Allerhöchsten Herrscherhauses (...) haben von Se. Excellenz, dem Patriarch-Erzbischof Metropoliten Brankovic vorgenommenen Einsegnungs- Zeremonie beigewohnt, und auch die großen Massen der Bevölkerung haben dem prunkvoll- düsteren Schauspiel großes Interesse zugewendet. Nach der kirchlichen Einsegnungs-Feierlichkeit (...) wurde der Sarg zu dem vor dem Kir-

42 „Ceremoniel der Überführung, Exponieren und Bestattung der Leiche weiland Seiner Majestät König Milans I."; in: Wiener Zeitung Nr. 37, 1. 
chenportal harrenden Galawagen getragen. Der Leichenzug setzte sich durch die Veithgasse dem Rennweg zu in Bewegung. Gegenüber der Kirche standen in Doppelreihen serbische Studenten in Trauerkleidung. Sie grüßten mit Ehrerbietung ihren vorüberfahrenden toten Herrscher. Dem Zuge wurde ein schwarzes griechisches Kreuz vorangetragen, auf dem in silbernen Lettern der Name König Milans I. und rückwärts die Zahl 1901 stand. Ein Zug Husaren eröffneten den Kondukt. (...) und nun kamen zwei sechsspännige Hofwagen. Dann kam der Leichenwagen, welcher von sechs reich und schwarz geschirrten Rappen gezogen wurde. (...) Den Leichenwagen geleiteten an beiden Seiten vier Edelknaben mit brennenden Wachsfak$\operatorname{keln}(\ldots) \mathrm{Zu}$ beiden Seiten bildete Leibgarden-Infanterie ein ambulantes Spalier. Unmittelbar hinter dem Sarge schritt Se. Majestät der Kaiser mit Ihren k. u. k. Hoheiten den durchlauchtigsten Herren Erzherzogen. (...) Auf dem ganzen Wege dahin drängte sich eine riesige Menschenmenge, die an Zahl zunahm, je näher der Bahnhof war. (...) Vor dem Hofwartesaal hielt der Leichenwagen (...) und Hofrat Ritter von Loebenstein leitete nun im Bahnhof die Einwaggonierung der sterblichen Überreste Sr. Majestät König Milans. (...) In offizieller Eigenschaft begleiteten die Leiche des Königs nach Karlowits und zur Bestattung ins Kloster Krusedol der Metropolit von Karlowits Patriarch-Erzbischof Georg Brankovic mit seinen beiden geistlichen Begleitern." ${ }^{43}$

\section{Paradigmenwechsel}

Die höfischen Trauerfeierlichkeiten für König Milan kündigten gleichsam symbolisch den Paradigmenwechsel in den Beziehungen zwischen Österreich-Ungarn und Serbien an. Nach der Ermordung des letzten Obrenović Monarchen Aleksandar im Jahre 1903, wuchsen unter der Karadjordje Dynastie die Konflikte mit der Donaumonarchie. Die Regierungen der meisten Staaten steuerten mit einer von Nationalismus und Imperialismus geprägten Bündnispolitik auf die „Urkatastrophe Europas“, den Ersten Weltkrieg 1914-1918, zu. Den Anlass, aber nicht die Ursache sollte schließlich das Attentat auf den österreichischen Thronfolger Franz Ferdinand vom 28. Juni 1914 bilden, der das schwärzeste Kapitel der österreichisch-serbischen Geschichte darstellt. Am 16. September 1908 verabredeten der österreichische Außenminister Alois Lexa Freiherr von Aehrenthal und der russische Außenminister Alexander Petrowitsch Iswolski auf Schloss Buchlau in Böhmen, dass Österreich Bosnien und Herzegowina erhalten, Russland im Gegenzug die Unterstützung der k. u.k. Monarchie für

${ }^{43}$ Kleine Chronik/König Milan; in: Wiener Zeitung, Nr. 39, den 16. Februar 1901, 2. 
die exklusiven russischen Durchfahrtsrechte durch den Bosporus und die Dardanellen gewinnen sollte. ${ }^{44}$ Das Jahr 1908 erschien als ein passender Zeitpunkt für Österreich-Ungarn die beiden Provinzen zu annektieren, da das Osmanische Reich nach der Revolution der Jungtürken einerseits politisch geschwächt war, andererseits aber auch wegen seiner Versprechen einer inneren Reform für Bosnien-Herzegowina als interessante Alternative erschien, zumal der Verwaltungsvertrag mit dem Osmanischen Reich nach 30 Jahren, also 1908 auslief. Anlässlich seines Namenstages am 4. Oktober verfügte der seit 1848 regierende Franz Joseph I. per Handschreiben „die Rechte Meiner Souveränität auf Bosnien und die Herzegowina zu erstrecken und die für Mein Haus geltende Erbfolgeordnung auch für diese Länder in Wirksamkeit zu setzen, sowie ihnen gleichzeitig verfassungsmäßige Einrichtungen zu gewähren“. ${ }^{45}$ Dieser Beschluss wurde am 5. Oktober 1908 vollzogen. Die Annexion richtete sich nicht nur gegen das Osmanische Reich, sondern auch gegen Serbien, das unter König Petar Karađorđević versuchte, alle Südslawen in einem Staat zu einen (Panserbismus). Zwischen beiden Ländern bestand seit 1906 außerdem ein scharfer Zollkonflikt, der sogenannte Schweinekrieg. ${ }^{46}$

Im Verlauf der Krise 1908 schlug Generalstabschef Franz Conrad von Hötzendorf mehrmals vor, bei der Gelegenheit auch Serbien zu erobern. Montenegro sollte ebenfalls ausgeschaltet werden oder wenigstens eine „Einengung" erfahren. Die Südslawen sollten einen Komplex im Rahmen der Monarchie bilden und dem Habsburgerreich, wie Bayern dem Deutschen Reich, untergeordnet werden. Weiters strebte er damals die Gewinnung Albaniens, des westlichen Mazedoniens und Montenegros an, mit dem strategischen Ziel, Saloniki als österreichische Bastion an der Ägäis zu etablieren. Sein imperialistisches Ziel war die Vereinigung aller West- und Südslawen unter österreichischer Herrschaft, was er mit der missionarischen Idee einer Stärkung der christlichen Kultur rechtfertigte. ${ }^{47}$

Diese Pläne wurden von Außenminister Alois Lexa von Ährenthal zurückgewiesen. Die Annexion führte zu wütenden Protesten im Osmanischen Reich, in Serbien sowie in Russland, wo panslawistische Strömungen verbreitet waren. Die dem Zarenreich als Gegenleistung zugesprochene freie Durchfahrt durch die Dardanellen scheiterte am Einspruch der Briten.

${ }^{44}$ Gerhard Zimmer, Gewaltsame territoriale Veränderungen und ihre völkerrechtliche Legitimation (Berlin: Duncker \& Humblot, 1971), 117.

${ }^{45}$ Josip Frank, „Die Eingliederung Bosniens und der Herzegowina“, in: Alfred von Berger et al. (Hrsg.), Österreichische Rundschau (Wien: Fromme, 1908), Band XVII, 160-3.

46 Christopher Clark, Die Schlafwandler. Wie Europa in den Ersten Weltkrieg zog (München: DVA, 2013), 70.

${ }^{47}$ Feldmarschall Conrad von Hötzendorf, Aus meiner Dienstzeit 1906-1918. Band 1: Die Zeit der Annexionskrise 1906-1909 (Wien/Berlin, 1921), 59, 537, 615. 
Daher fühlte sich Russland zum zweiten Mal seit dem Berliner Kongress hintergangen. Es bestand einige Wochen lang akute Kriegsgefahr, da das Vereinigte Königreich und Russland damit drohten, das Osmanische Reich zum Nachteil Österreichs in seiner alten Rechtsstellung wieder einzusetzen. Obwohl ein europäischer Krieg noch vermieden werden konnte, ist die Annexionskrise als wichtiger Schritt auf dem Weg zum Ersten Weltkrieg anzusehen. Im Dezember 1911 entließ Franz Joseph vorläufig den Generalstabschef Franz Conrad von Hötzendorf. Die Begründung lag in den fortwährenden Präventivkriegsforderungen Conrads, die der Kaiser rundweg ablehnte. Noch bei einer Audienz am 15. November 1911 machte der Kaiser dem davon unbeeindruckten Generalstabschef Conrad dazu Vorhaltungen: „Diese fortwährenden Angriffe, besonders die Vorwürfe wegen Italien und des Balkan, die sich immer wiederholen, die richten sich gegen mich, die Politik mache ich, das ist meine Politik! Meine Politik ist eine Politik des Friedens. Dieser Meiner Politik müssen sich alle anbequemen." 48

\section{QUELLEN UND LITERATURVERZEICHNIS}

- Allerhöchstes Patent vom 2. Dezember 1848.

- Amstadt, Jakob. Die k. k. Militaergrenze 1522-1881. Würzburg: Dissertation, 1969.

- Angermeier, Heinz. „Der österreichische Imperialismus des Feldmarschalls Conrad von Hötzendorf." In: Dieter Albrecht (Hrsg), Festschrift für Max Spindler zum 75. Geburtstag. München: C.H.Beck, 1969.

- Basch-Ritter, Renate. Österreich-Ungarn in Wort und Bild, /Menschen und Länder. Graz-Wien-Köln, 1989.

- Bönisch, Georg. „Durchlaucht, das ist eine Revolution“. Der Spiegel Geschichte, 3 (2014).

- Boue, Ami. Die Europäische Türkei. Wien: Mell, 2008.

- Buchmann, Bertrand Michael. Österreich und das Osmanische Reich. Eine bilaterale Geschichte. Wien: Facultas, 1999.

- Clark, Christopher. Die Schlafwandler. Wie Europa in den Ersten Weltkrieg zog. München: DVA, 2013.

- Denkschrift zum 75-jährigen Jubiläum der Serbisch - orthodoxen Kirchenund Schulgemeinde in Wien 1860-1935. Beograd, 1936.

${ }^{48}$ Heinz Angermeier, „Der österreichische Imperialismus des Feldmarschalls Conrad von Hötzendorf“, in: Dieter Albrecht (Hrsg), Festschrift für Max Spindler zum 75. Geburtstag (München: C. H. Beck, 1969), 784. 
- „Der Berliner Kongress und die Aufteilung des Balkans“, Der Erste Weltkriegww1.habsburger. net > kapitel > der-berli...; abgefragt am 24.8.2016.

- Drury, Ian. The Russo-Turkish War 1877. London: Osprey, 2012.

- Frank, Josip. „Die Eingliederung Bosniens und der Herzegowina“. In: Alfred von Berger et al.(Hrsg.), Österreichische Rundschau. Wien: Fromme, 1908, Band XVII, 160-3.

- Geiss Imanuel (Hrsg.). Der Berliner Kongreß 1878. Protokolle und Materialien. Boppard am Rhein: Boldt, 1978.

- Habsburg, Karl von. „Vorwort zur Aufsatzsammlung ,Kaiser Franz Joseph I zum 100. Todestag' ". History. Kurier das österreichische Geschichtsmagazin, 1 (2016).

- Holm Sundhaussen. Geschichte Serbiens. Wien: Böhlau, 2007.

- Hötzendorf, Conrad von. Aus meiner Dienstzeit 1906-1918. Band 1: Die Zeit der Annexionskrise 1906-1909. Wien/Berlin, 1921.

- „(Klein-)Krieg entlang der Militärgrenze“. Die Welt der Habsburger, www.habsburger. net >Kapitel > klein-kri...; abgefragt am 19.8.2016.

- Konrad, Helmut. Österreich-Ungarn: Nationale Fragen in der Donaumonarchie; Universal-Lexikon, www.vga. at/index..abgefragt 30.8.2016.

- Lackner, Herbert. „Der verklärte Kaiser“, Historie Profil Thema das Beste aus Österreichs unabhängigen Nachrichtenmagazin, 1 (2016).

- Matić, Andrija. Nešto iz života i rada društva 'Zora' ; književni rad srpskog đačkog društva u Beču. Wien, 1875.

- Medaković, Dejan. Serben in Wien. Novi Sad: Prometej, 2001.

- Mišić, Vukosava. Postanak i razvitak Srpske Pravoslavne crkve u Beču, Beograd: Štamparija Sv. Save, 1929.

- Moritsch, Andreas. Der Austroslawismus : ein verfrühtes Konzept zur politischen Neugestaltung Mitteleuropas, Wien / Köln / Weimar: Internationalen Zentrums für Europäische Nationalismus- und Minderheitenforschung, 1995.

- Österreichisches Biographisches Lexikon 1815-1950 (ÖBL). Wien: Verlag der Österreichischen Akademie der Wissenschaften, 1983.

- Plöchl, Willibald M. Die Wiener Orthodoxen Griechen. Wien: Verlag des Verbandes der Wissenschaftlichen Gesellschaften Österreichs, 1983.

- Rohrbach, Wolfgang. Auf den Spuren der Serben Österreichs/Eine historisch-soziologische Aufsatzsammlung, Wien: Österreichisch-Serbischen Gesellschaft, 2013.

- Sommeregger, Karl. „Philippovic von Philippsberg, Josef Freiherr“. In: Allgemeine Deutsche Biographie. Leipzig: Duncker \& Humblot, 1907, Band 53, 54.

- Stajić, Vasa. Jovan Jovanović Zmaj. Novi Sad: Slavija, 1935. 
- Stefanovic-Vilovsky, Theodor. Die Serben im südlichen Ungarn, in Dalmatien, Bosnien und in der Herzegovina. Wien und Teschen, 1884.

- Stojic, Hana. Phraseologische Untersuchungen zu tierbezogenen Redewendungen Deutsch - B/K/S. Wien: Diplomarbeit, 2009.

- Wien seit 60 Jahren. Zur Erinnerung an die Feier der 60-jährigen Regierung Seiner Majestät des Kaisers Franz Josef I. der Jugend Wiens gewidmet von dem Gemeinderate ihrer Vaterstadt. Wien: Gerlach \& Wiedling, 1908.

- Wiener Zeitung, Februar 1901.

- Wurzbach, Constantin von. Biographisches Lexikon des Kaisertums Österreich. Wien: Kaiserlich-königliche Hof- und Staatsdruckerei, 1864-1870.

- Zimmer, Gerhard. Gewaltsame territoriale Veränderungen und ihre völkerrechtliche Legitimation. Berlin: Duncker \& Humblot, 1971.

Wolfgang Rohrbach

CAR FRANJO JOSIF PRVI I SRBI 1848-1908.

Rezime

Stogodišnjica smrti cara Franje Josifa I (umro 21. novembra 1916) predstavljala je u Austriji povod za izdavanje velikog broja publikacija o životu i 68-godišnjoj vladavini popularnog monarha. Dok se politička previranja između Rusije, Nemačke, odnosno Pruske, Turske i Italije pretežno prikazuju umereno, Srbija je opisana jednostrano, sa težištem na deset poslednjih godina careve vladavine. Da bi se ublažio taj nedostatak, prilog osvetljava period od 1848. godine (stupanje na vlast Franje Josifa I) do 1908. (aneksija Bosne i Hercegovine). Danas se o prijateljskim odnosima i sporazumu cara Franje Josifa I sa kraljem Milanom Obrenovićem, kao i poglavarima Srpske pravoslavne crkve, srpskom vojskom, naučnicima i umetnicima zna mnogo više nego pre sto godina. Na taj način je uvreženom mišljenju o tome da su u odnosima Austrije sa Srbijom tokom vekova prevladavali politički nesporazumi, suprotstavljena naučno zasnovana argumentacija. Ovaj rad dokumentuje i interpretira zaboravljeno zajedništvo i saradnju Austrije i Srbije od 1848. godine. Na zahtev cara Franje Josifa I mnoge vojne, naučne i političke položaje zauzimali su Srbi; srpski umetnici su angažovani u toku rekonstrukcije carskog grada Beča. Na Bečkom univerzitetu 1849. godine osnovan je prvi institut za slavistiku u svetu. Bečki univerzitet je narednih godina postao raskrsnica naučnog i kulturnog razvoja Balkana. 
KLJUČNE REČI: kompenzacija, austroslavizam, Banat, Berlinski kongres, Bosna, Milan I Obrenović, Vojna granica (Krajina), okupacija, revolucionarna 1848/49, Ringštrase

THE EMPEROR FRANZ JOSEPH I AND SERBS 1848-1908

\section{Summary}

A century from death of Emperor Franz Joseph I (+21.11.1916) triggered a great number of publications about life and almost seven decades long reign of a popular monarch. As the political struggle between Russia, Prussia, Italy and Ottoman Empire are depicted with moderation, Serbia is described unidimensional, with an emphasis on the last decade of Emperors rule. In order to remedy this shortcoming, this contribution is focusing on a period between 1848 and 1908. Today we know much more about relations between Franz Joseph and King Milan Obrenović, as well as with dignitaries of Serbian Orthodox Church, and military, academic and artistic elite. It is, therefore, possible to refute entrenched notions about constant enmity and hostility between Austria and Serbia. In this work, an emphasis is put on cooperation between Austria and Serbia from 1848, when Serbs at Emperors request held a number of important political and military positions, whereas Serbian artists took part in the reconstruction of Imperial Vienna. The university of Vienna hosted the oldest institute for slavistic (1849), becoming, therefore, a crossroad of the cultural and social development of the Balkans.

KEYWORDS: compensation, Austroslavism, Banat, Berlin Congress, Bosnia, Milan I Obrenović, Military Border (Krajina), occupation, revolutionary years 1848/49, Ringstrasse 